\title{
Correspondence
}

\section{Personal resilience for psychiatrists: systematic review}

I read with interest this article ${ }^{1}$ which explores the factors that promote and maintain psychiatrists' well-being, particularly personal, workplace and non-work-related factors such as increased self-awareness, extending job roles, discrete work activities, and/or support from family or social environment.

John. D. Yoon and Brendan M. Daley, studying the association between a sense of calling and physician well-being, ${ }^{2}$ reported that a higher sense of calling in primary care physicians and psychiatrists was associated with an increased level of job satisfaction and resilience from burn-out. This reflects the deeper sense of meaning and purpose that work can bring, which generates and even sustains motivation and enables working with vision. However, there are reported challenges relating to the bureaucratic and technological demands that physicians experience, which mean the sense of calling can be hard to sustain.

A report from the Association of American Medical Colleges published in February 2019 highlights the misalignment between practitioners' values and practices and those of organisations, which can contribute to burn-out and diminished well-being.

Authors Adam M. Brenner and John Coverdale, in their update on trainee wellness, ${ }^{3}$ report on voluntary resident-led peer group reflective practice for medical students as an intervention for social connectedness. Although the study was of small sample size and lacked a control group, social belonging appeared to be a positive predictor of well-being, diminished imposter syndrome and tolerance of diverse perspectives, suggesting that this model deserves further attention as a potential means of improving resilience in trainees and professionals or psychiatrists.

The authors quote in their update Winston Churchill's famous saying: 'Now this is not the end. It is not even the beginning of the end. but it is, perhaps, the end of the beginning'. These words express hope for momentum towards victory; we are still in the early stages of addressing burn-out and improving well-being, but perhaps we are moving in the right direction.

Christine Montross, in her book Falling Into the Fire: A Psychiatrist's Encounters with the Mind in Crisis, ${ }^{4}$ describes 'patients who are so difficult to diagnose or treat - uncertainty it arises', 'I hold my trust in medicine up to the light, I see that it is full of cracks and seams. In some places it is luminous. In others it is opaque. And yet I practice'. She discusses how over time she has developed trust in the daily work of talking, treating and attempting to heal: 'you have to be anchored to the shore - to the people and things that are central to your own life'.

Francis Stella Sophia Senthil, Trust Locum Consultant Psychiatrist, Lincolnshire Partnership Foundation NHS Trust. Email: sophiasenthil@doctors.org.uk

1 Howard R, Kirkley C, Baylis N. Personal resilience in psychiatrists: systematic review. BJPsych Bull 2019; doi: 10.1192/bjb.2019.12.
2 Yoon JD, Daley BM, Curlin FA. The association between a sense of calling and physician well-being: a national study of primary care physicians and psychiatrists. Acad Psychiatry 2017; 41(2): 167-73.

3 Brenner AM, Coverdale J, Guerrero APS, Balon R, Beresin EV, Louie AK, et al. An update on trainee wellness: some progress and a long way to go. Acad Psychiatry 2019; 43(4): 357-60.

4 Montrose C. Falling Into the Fire: A Psychiatrist's Encounters with the Mind in Crisis. Penguin Books, 2014.

doi:10.1192/bjb.2019.69

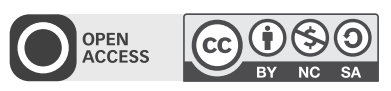

(c) The Author 2019. This is an Open Access article, distributed under the terms of the Creative Commons Attribution-NonCommercial-ShareAlike licence (http://creativecommons.org/licenses/by-nc-sa/4.0/), which permits non-commercial re-use, distribution, and reproduction in any medium, provided the same Creative Commons licence is included and the original work is properly cited. The written permission of Cambridge University Press must be obtained for commercial re-use.

\section{Addressing shame in medical professional identity: is there such a thing as a good enough doctor?}

The author of 'Addressing shame in medical professional identity ${ }^{11}$ is to be congratulated for bringing this topic to the fore of our consciousness. It is welcomed along with the recent surge of popular literature focusing on the emotional challenges of medical practice (particularly among trainees), including Adam Kay's This is Going To Hurt and Danielle Ofri's What Doctors Feel.

We know that shame affects the self-care of doctors; it increases the risk of mental health problems by making us less likely to access support when needed. Mental health is currently a critical issue, especially among junior doctors, who have higher levels of clinically significant mental health problems than the general population; ${ }^{2,3}$ junior trainees are less likely to disclose mental distress, ${ }^{2}$ and the more junior a doctor is, the less likely they are to know how to access support. ${ }^{3}$ Further, failure to disclose mental distress and access help perpetuates stigma. There remains a high rate of presenteeism, ${ }^{2}$ probably mediated by shame.

We also know that shame affects patient care experiences. The author notes that shame leads to reticence among doctors to disclosure errors. This means that teams are less able to learn from the mistakes of members, and the service does not have the opportunity to improve.

The author discusses what is not helpful in addressing shame (mandated reflective writing) but is vague on practical solutions - although there is a citation of Brown, reflecting that self-compassion is the antidote to shame. To our minds, this notion comes from Prof. Paul Gilbert's school of thinking and his team's extensive research on compassion-focused therapy (CFT) to address shame in a variety of clinical settings. They found that CFT training (a three-day workshop) for healthcare providers increased self-compassion and reduced self-critical judgement in clinicians. ${ }^{4}$ 